\title{
Elevating and sustaining the component of clinical teaching by targeting teachers in medical institutions
}

\author{
Shrivastava, S. R., Shrivastava, P. S.
}

\begin{abstract}
Clinical teaching in medicine plays an important role in the making of a competent and skilled health care professional. It is a fact that owing to the recent rise in the burden on the health system because of an augmented rise in the number of patients visiting hospitals, including tertiary medical colleges, the time for clinical teaching has significantly reduced. However, acknowledging the scope of clinical teaching in the making of a competent health care professional, the need of the hour is that the medical colleges and the individual departments should give immense attention towards delivering high-quality teaching. As the teachers remain the most important stakeholder in effective clinical teaching, they should be aware about the existing challenges and the ways to address them. In conclusion, clinical teaching needs to be improved and streamlined in all the medical institutions. The major responsibility of effective delivery of clinical teaching lies with the medical teachers and it is high time that they understand the prevailing challenges and work with an aim to overcome them and eventually enhance the effectiveness of teaching.
\end{abstract}

Keywords: Clinical teaching, Teachers, Feedback, Medical education

\section{Introduction}

Clinical teaching in medicine plays an important role in the making of a competent and skilled health care professional (Koharchik \& Redding, 2016). Effective clinical teaching helps a medical student to apply the medical knowledge into clinical practice and simultaneously develop clinical reasoning, critical thinking and problem- solving skills. This plays an important role in the making of a successful clinical practitioner and also reduces the probability of prescribing unnecessary laboratory investigations. Moreover, via role modelling, the students learn about the importance of doctor-patient communication

Department of Community Medicine, Shri Sathya Sai Medical College and Research Institute, Sri Balaji Vidyapeeth - Deemed to be University, Ammapettai, Nellikuppam, Chengalpet District, Tamil Nadu, India

Corresponding author:

Dr. Saurabh RamBihariLal Shrivastava drshrishri2008@gmail.com

DOI: http://doi.org/10.4038/seajme.v15i2.373 and the need to be professional for a successful career (Koharchik \& Redding, 2016).In continuation, clinical teaching prepares a medical student to the real-life challenges in the patient care and accordingly acquire the leadership skills, learn to become a member of the health team, and eventually become a lifelong and self-directed learner (Koharchik \& Redding, 2016; Vanka \& Hovaguimian; 2019).

\section{Strengthening clinical teaching}

Considering that the medical students who are trained better in clinics by their teachers have better skills and comprehension, they will themselves play an important role in improving the patient outcomes. This creates enough justification for the teachers to allocate dedicated time towards clinical teaching and thus producing a competent physician (Ramani and Leinster; 2008). It is a fact that owing to the recent rise in the burden on the health system because of an augmented rise in the number of patients visiting hospitals, including tertiary 
medical colleges, the time for clinical teaching has significantly reduced (Vanka \& Hovaguimian; 2019). Moreover, no longer clinical teaching is the primary responsibility for the teachers, and they have to simultaneously discharge the roles of an administrator, evaluator, a researcher, and a mentor (Vanka \& Hovaguimian; 2019). However, acknowledging the scope of clinical teaching in the making of a competent health care professional, the need of the hour is that the medical colleges and the individual departments should give immense attention towards delivering high-quality teaching (Koharchik \& Redding, 2016; Vanka \& Hovaguimian; 2019; Ramani \& Leinster; 2008).

\section{Strategies to improve clinical teaching}

This leads us to look for answers on how to elevate and sustain clinical teaching in medical institutions? The first and foremost thing will be to not give undue importance to the research accomplishments in deciding the capability / salary increment / promotion of a faculty member (Shrivastava and Shrivastava, 2020). We agree that research is required even in the field of medical education, but in no ways, it should be considered more superior than the teaching or administrative roles expected of a faculty member. In settings, wherein faculty members are very much busy, the practice of one-minute preceptor, or peer teaching or near peer-teaching can be employed, as it will ensure that the process of teaching-learning continues.

The next strategy could be identifying a core group of faculty members who are assigned the responsibility of clinical teaching as their primary role and can be ably supported by the rest of the teaching staff (Ramani \& Leinster; 2008). The best way to execute the same in a medical institution will be through the adoption of a balanced scorecard and evaluate the performance of a staff on the basis of their discharged roles (Ramani \& Leinster; 2008; Shrivastava \& Shrivastava, 2020).

\section{Teachers and Clinical teaching}

As the teachers remain the most important stakeholder in effective clinical teaching, they should be aware about the existing challenges and the ways to address them. The teachers have to decide before each session about the competencies being covered, the ways in which they will be covered and mode of engagement of students (Vanka \& Hovaguimian; 2019; Ramani \& Leinster; 2008). In order to engage learners of different level simultaneously, a teacher can give assignments to the students well in advance, divide bedside tasks among them and use senior students for near peer teaching (Koharchik \& Redding, 2016; Vanka \& Hovaguimian; 2019). Further, the teachers should not be intimidated by the fact that the clinical discussion can go in some directions where they are not confident. The best way is to accept our limitations and aim to learn together as it is extremely difficult to master all aspects of medicine (Ramani \& Leinster; 2008).

In order to enhance the participation of patients and neutralize their inhibitions or concerns to be a part of clinical teaching, the major onus lies with the teacher and other hospital staff. It is the responsibility of the teachers to make patients believe that they should participate in the training of medical students and it can be easily accomplished by giving the patients a proper introduction, setting of ground rules and the assurance that their interests will be safeguarded (Vanka \& Hovaguimian; 2019; Ramani \& Leinster; 2008). The teachers have to ensure that they give timely feedback to the learners about their performance and help them to become better. It is an encouraging step to evaluate the performance of a teacher and can be done by obtaining feedback from the students or peer-teachers or by microteaching or by going through the videotaping of teaching encounters (Koharchik \& Redding, 2016; Vanka \& Hovaguimian; 2019; Ramani \& Leinster; 2008; Damp et al., 2016).

In-fact, based on the results, the medical education unit can take the lead to address the needs of the teachers and improve teaching skills. At the same time, faculty members can be encouraged to join in medical education 
courses or fellowship to enhance their teachinglearning skills (Damp et al., 2016). We all will agree that most of the successful clinical teachers have mastered the art of teaching by trial-and-error, through guidance and mentoring of their teachers. Thus, it is the need of the hour to invest and emphasize on the domain of clinical teaching so that we can produce a better cohort of doctors, who themselves are good teachers and plays an important role in the provision of quality assured patient care (Koharchik \& Redding, 2016; Vanka \& Hovaguimian; 2019; Ramani \& Leinster; 2008).

\section{Conclusion}

In conclusion, clinical teaching needs to be improved and streamlined in all the medical institutions. The major responsibility of effective delivery of clinical teaching lies with the medical teachers and it is high time that they understand the prevailing challenges and work with an aim to overcome them and eventually enhance the effectiveness of teaching.

\section{References}

Damp, J.B., Dewey, C.M., Wells, Q., Horn, L., Kroop, S.F., \& Mendes, L. (2016) Faculty development on clinical teaching skills: An effective model for the busy clinician. Journal of Medical Education and Curricular Development, 3, pp. JMECD.S40798.

Koharchik, L. \& Redding, S.R. (2016) Strategies for successful clinical teaching. American Journal of Nursing, 116, 7, pp. 62-65.

Ramani, S. \& Leinster, S. (2008) AMEE Guide no. 34: Teaching in the clinical environment. Medical Teacher, 30, 4, pp. 347-364.

Shrivastava, S.R., \& Shrivastava, P.S. (2020) Balanced Scorecard for teaching faculty members working in a medical college. BLDE University Journal of Health Sciences, 5, 1, pp. 83-84.

Vanka, A. \& Hovaguimian, A. (2019) Teaching strategies for the clinical environment. Clinical Teacher, 16, 6, pp. 570-574. 